\title{
The pathophysiology of hyperuricaemia and its possible relationship to cardiovascular disease, morbidity and mortality
}

\author{
David Gustafsson ${ }^{1 *}$ and Robert Unwin ${ }^{2}$
}

\begin{abstract}
Uric acid is the end product of purine metabolism in humans. High levels are causative in gout and urolithiasis. Hyperuricaemia has also been implicated in the pathophysiology of hypertension, chronic kidney disease (CKD), congestive heart failure (CHF), the metabolic syndrome, type 2 diabetes mellitus (T2DM), and atherosclerosis, with or without cardiovascular events. This article briefly reviews uric acid metabolism and summarizes the current literature on hyperuricaemia in cardiovascular disease and related co-morbidities, and emerging treatment options.
\end{abstract}

Keywords: Uric acid, Urate, Hypertension, Chronic kidney disease, Congestive heart failure, Type 2 diabetes mellitus, Metabolic syndrome, Cardiovascular events, Atherosclerosis

\section{Review}

\section{Physiology and pharmacology}

Uric acid largely exists as urate (the ionized form, pKa is 5.8) at neutral $\mathrm{pH}$. It is the end product of purine metabolism in humans. High serum levels of urate (hyperuricaemia) are causative in gout and urolithiasis, due to the formation and deposition of monosodium urate crystals. Urate is singly charged at neutral $\mathrm{pH}$ and at a concentration of $6.8 \mathrm{mg} /$ $\mathrm{dL}(0.40 \mathrm{mmol} / \mathrm{L})$ in human serum, crystals can form spontaneously. The solubility of urate decreases with increasing local sodium concentration, and decreasing temperature and $\mathrm{pH}$ [1]. The latter is an important factor in urate stoneformation in patients with acidic urine. The serum level of urate in man considered to be 'normal' varies among laboratories and in publications, but a range of $3.5 \mathrm{mg} / \mathrm{dL}$ $(0.2 \mathrm{mmol} / \mathrm{L})$ to $7.0 \mathrm{mg} / \mathrm{dL}(0.4 \mathrm{mmol} / \mathrm{L})$ is often quoted. Serum urate is usually $0.5-1 \mathrm{mg} / \mathrm{dL}(0.03-0.06 \mathrm{mmol} / \mathrm{L})$ lower in women compared with men. Serum urate levels in men have increased gradually from $3.5 \mathrm{mg} / \mathrm{dl}(0.2 \mathrm{mmol} / \mathrm{L})$ in the $1920 \mathrm{~s}$ to $6.0 \mathrm{mg} / \mathrm{dL}(0.35 \mathrm{mmol} / \mathrm{L})$ in the $1970 \mathrm{~s}$ [2]. However, no explanation for this observation has been given, but it is probably related to changes in diet, e.g., increased intake of fructose.

\footnotetext{
* Correspondence: david.gustafsson@astrazeneca.com

'Bioscience, CVMD iMED, AstraZeneca R\&D Mölndal, Mölndal, Sweden Full list of author information is available at the end of the article
}

The serum urate level depends on dietary purines, the degradation of endogenous purines, and the renal and intestinal excretion of urate. The dominating factor contributing to hyperuricaemia is under-excretion of urate [1].

\section{Diet}

High ingestion of purine sources (animal protein - meat and seafood - and beer) and alcohol increase the demands on purine elimination, while coffee and vitamin $\mathrm{C}$ reduce demand. Also, high intake of fructose increases serum urate, a relationship that has been ascribed to fructose phosphorylation in the liver with subsequent ATP depletion and regeneration $[1,3]$.

\section{Purine metabolism}

Increased cell turnover (e.g., haemolysis, tumour growth and large tumour necrosis) leads to increased production of adenosine, inosine and guanosine. These are degraded to hypoxantine and xanthine, which are the substrates for the widely distributed xanthine oxidase $(\mathrm{XO})$ in the formation of uric acid (Figure 1). Allopurinol and febuxostat are inhibitors of $\mathrm{XO}$ and reduce uric acid formation. In man and some higher primates, uric acid is the endproduct of purine metabolism. However, most mammals can degrade uric acid further to water-soluble allantoin by the enzyme uricase and as a result serum urate levels are about $1 / 10$ of human values [1]. Pegloticase is a pegylated 


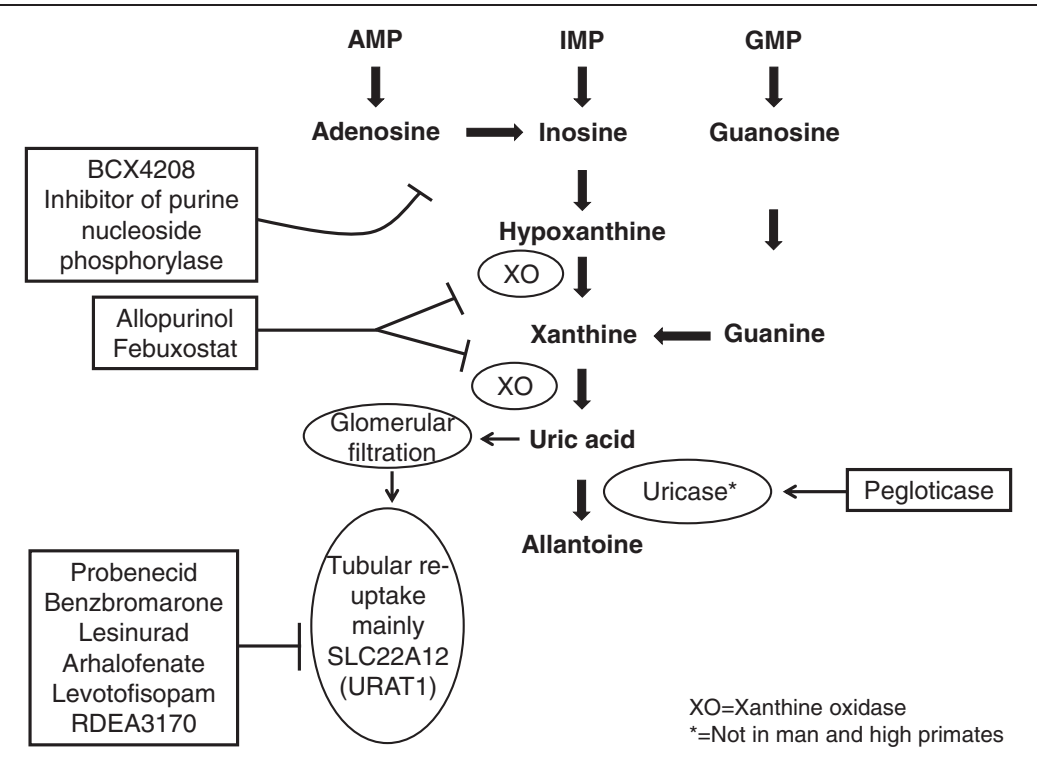

Figure 1 Schematic representation of uric acid formation and elimination showing the drugs that can affect both.

uricase that reduces urate levels by increasing its metabolism and it can be used therapeutically in man [4].

\section{Urate excretion}

Urinary excretion accounts for two-thirds of total elimination of uric acid and the remainder is excreted in faeces. Urate is not protein bound and is freely filtered at the glomerulus, but up to $90 \%$ of filtered urate is reabsorbed (Figure 1). The main transporters responsible for tubular reabsorption are SLC22A12 (URAT1 - dominant expression is in the kidney and apical in tubular cells) and SLC2A9 (GLUT9 - widely expressed, but most likely basolateral in tubular cells), while SLC22A11 (OAT4 - apical) is less important and the evidence is weaker [5]. There also seems to be tubular secretion of urate with some evidence existing for ABCG2, SLC17A1, SLC17A3 (apical) and SLC22A6 (OAT1) and SLC22A8 (OAT3) (both basolateral) [5]. Probenecid, benzbromarone and lesinurad all inhibit URAT1, thereby reducing serum urate levels. Non-renal elimination of urate is poorly understood: a recent publication suggests that uric acid is also secreted directly into the intestinal lumen, but not via the bile [6]; studies in Caco2 cells indicate that ABCG2 is important for this route of urate elimination.

\section{Genetic information}

Genome-wide association studies (GWAS) have implicated a number of genes associated with serum urate and gout. Hereditary renal hypouricaemia type 1 is due to loss of function mutations in URAT1 (SLC22A12) and is relatively common in Japan, and can be complicated by nephrolithiasis or exercise-induced acute renal failure [7]. URAT1 has been genetically associated with urate levels, though no genetic association has been demonstrated for URAT1 and gout [8,9]. SLC2A9 (GLUT9) is responsible for approximately $4 \%$ of the variance in serum urate levels and has an association with gout [8,9]. It is a glucose, fructose, and uric acid transporter, although its greatest affinity is for uric acid. It reabsorbs urate from the proximal renal tubule and may also be expressed in the distal nephron (and the liver and intestine); a homozygous loss-of-function mutation causes severe hereditary renal hypouricaemia type 2 [10]. ABCG2 is a renal and extra-renal urate exporter responsible for $<1 \%$ of the variance of serum urate, although it has also been associated with gout $[8,9]$. Recently a large GWAS (>140,000 individuals) was published [11]. Of loci described previously 10 were confirmed and 18 new loci were identified. However, none of the new loci seemed to be candidates for urate transport but were instead related to glycolysis, glucose, insulin and pyruvate, indicating an importance in de novo purine synthesis and thereby uric acid production [11]. It was also found that alleles associated with increased serum urate concentrations were associated with increased risk of gout. Finally, the rare autosomal dominant diseases collectively known as uromodulin-associated kidney diseas (UAKD) should also be mentioned. These are characterized by hyperuricaemia, gout, and finally end stage renal disease. They are caused by mutations in the renal specific gene UMOD [12]. This suggests a coupling between urate transport and the UMOD gene product uromodulin, also known as Tamm Horsfall protein, although the details are still unclear. Uromodulin is produced by the epithelial cells of the thick ascending limb of the loop of Henle and is secreted into the urine. It is possible that uromodulin might regulate sodium transport in the thick ascending 
limb and that hyperuricaemia in UAKD is secondary to hypovolaemia and increased reabsorption of urate along the proximal tubule.

\section{Treatment of gout}

Gout is the result of monosodium urate crystals in joints, which trigger the NALP3 (cryopyrin) inflammasome and release of pro-inflammatory cytokines, especially IL- $1 \beta$. Gouty arthritis is often intermittent, but can be chronic, joint destructive and deforming, and persistently painful. Tophi (large crystal deposits) can form in longstanding disease. Gout affects $1-4 \%$ of adults (it is more common in the USA) and its prevalence is increasing, probably due to changes in diet, increases in CKD (gout has a higher prevalence in CKD [13]), obesity, and a longer lifespan. Subjects with serum urate between 7 and $8 \mathrm{mg} / \mathrm{dL}(0.40$ $0.48 \mathrm{mmol} / \mathrm{L}$ ) have an accumulated risk of developing gout of $3 \%$, while those above $9 \mathrm{mg} / \mathrm{dL}(>0.54 \mathrm{mmol} / \mathrm{L})$ have an accumulated risk of $22 \%$. The American College of Rheumatology guidelines recommend a serum urate target level of $<6 \mathrm{mg} / \mathrm{dL}(<0.35 \mathrm{mmol} / \mathrm{L})$ in all gout cases and $<5 \mathrm{mg} / \mathrm{dL}(<0.3 \mathrm{mmol} / \mathrm{L})$ in gout with tophi [14]. The recommendation in Japan also includes reducing hyperuricaemia, even in the absence of gout, with lifestyle guidance or drugs if $>8 \mathrm{mg} / \mathrm{dL}(>0.48 \mathrm{mmol} / \mathrm{L})$ and certain conditions apply [15]. Gout is costly to Society, since those affected are often absent from work [16].

Standard treatment consists of acute anti-inflammatory drugs for gouty flares, followed by the long-term uratelowering therapy. Anti-inflammatory treatment aims at reducing the pain and swelling. Established treatments are NSAIDs and sometimes corticosteroids. Colchicine can be used as gout prophylaxis, especially when urate-lowering therapy is first introduced, but it is also used for acute gout. Drugs targeting IL-1 $\beta$ [4] are also effective in acute gout (e.g. rilonacept and canakinumab).

Primary urate-lowering therapy (Figure 1) is often initiated with a XO inhibitor such as allopurinol or febuxostat, but the number of patients achieving serum urate levels $<6 \mathrm{mg} / \mathrm{dL}(<0.35 \mathrm{mmol} / \mathrm{L})$ is in the range of 20 $40 \%$ for allopurinol and $45-67 \%$ for febuxostat (Phase III data [17]), indicating the need for additional therapies. Moreover, allopurinol can have both dose-related (e.g., gastrointestinal intolerance, rashes) and idiosyncratic side effects, which can be life-threatening and may by more frequent in Asians [16,18]. Examples of non-specific uricosuric drugs are the older URAT1 inhibitors probenecid (which also inhibits OAT1 and 3), which is still available in some countries, and benzbromarone, which has largely been withdrawn because of liver toxicity. Uricosuric drugs in clinical development are mainly URAT1 inhibitors, i.e., lesinurad (Phase III), arhalofenate (Phase II and also in development for diabetes), levotofisopam (Phase II and the S-enantiomer of
RS-tofisopam, an anxiolytic agent used in some countries) and RDEA3170 (Phase I) $[4,19,20]$. Lesinurad can achieve target serum urate levels when given with allopurinol or febuxostat in $60-100 \%$ of the patients, according to available Phase II data [16]. Use of the non-absorbable phosphate binder sevelamer can also decrease serum urate in haemodialysis patients, most likely the result of increased gastrointestinal elimination [21]. BCX4208, an inhibitor of purine nucleotide phosphorylase (an enzyme 'higher up' in the purine metabolic pathway), is in Phase II trial [4]. There are two pegylated uricase derivatives: pegloticase is approved for patients refractory to conventional treatments (mainly used in severe tophaceous gout) and pegadricase has been in Phase I trial and may still be in development [4]. These emerging therapies are aiming to improve efficacy and reduce side effects $[4,16]$.

\section{Pathophysiology of hyperuricaemia-associated conditions} The initial trigger of the 'inflammasome' is from the effect of monosodium urate crystals on cells of the monocyte/macrophage lineage [22]. This leads (via the NALP3 inflammasome) to secretion of IL-1 $\beta$, which then acts to recruit more inflammatory cells. The detailed mechanism underlying the secretion of IL- $1 \beta$ is not known, but cell damage leading to ATP release and activation of the P2X7 receptor may be involved. Potassium efflux may also be important, as well as generation of reactive oxygen species (ROS). Released IL- $1 \beta$ recruits other inflammatory cells and so amplifies the inflammatory reaction. The result is a burst of inflammatory mediator release. The inflammation spontaneously resolves, perhaps mediated by release of the anti-inflammatory cytokine TGF- $\beta$. The inflammasome is considered to be essential in gout and other crystalopathies, but its role in any associated pathology is less clear. It is also unclear if hyperuricaemia alone can initiate other pathological processes. What information is available, will be included with the discussion of various diseases associated with hyperuricaemia.

Multivariate analysis has been used to assess if serum urate is an independent risk factor for disease. A positive association has been found between urate levels and a number of important disorders, including hypertension, CKD, $\mathrm{CHF}$, the metabolic syndrome, T2DM, endothelial cell dysfunction, cardiovascular events, and fatty liver disease. The strength of these associations will be discussed below. There are also a few intervention studies, mostly with allopurinol, but these are small and may not be representative of the effects of lowering urate by different mechanisms.

It is important to mention that urate also plays an essential function in humans. The loss of uricase in higher primates parallels the similar loss of our ability to synthesize ascorbic acid, an important anti-oxidant, leading to the suggestion that urate may partially substitute for ascorbate in humans $[1,5,23]$. Both uric acid and ascorbic acid are 
strong reducing agents (electron donors) and potent antioxidants. In humans, the major extracellular antioxidant capacity of blood comes from urate, but urate can also be pro-oxidant depending on the conditions [5,23] (see also below under the metabolic syndrome). Epidemiological data suggest that urate may be important in neuroprotection. The brain is vulnerable to oxidative stress due to its high metabolic rate and high levels of unsaturated fatty acids. Thus, increased lipid peroxidation could be one explanation for the association found between reduced serum urate levels and CNS disorders such as multiple sclerosis (MS), AML, Parkinson's, Alzheimer's and Huntington's diseases. Patients with MS have significantly lower serum urate levels and there seem to be no reported cases of patients suffering from both MS and gout [24].

\section{Hypertension}

Animal models have shown that acute elevations of serum urate (e.g., by inhibition of uricase) induce a prompt rise in blood pressure and that chronic urate elevation maintains the rise in pressure and induces irreversible vascular damage and glomerular changes, and results in a form of saltsensitive hypertension $[25,26]$. The mechanisms suggested are a renin-angiotensin-aldosterone-dependent arteriolopathy, inhibition of neuronal nitric oxide synthase, and interstitial fibrosis and glomerulosclerosis with albuminuria. A meta-analysis of 11 studies showed that hyperuricaemia is associated with an increased risk of incident hypertension, independent of traditional risk factors. This risk appears more pronounced in younger individuals (with pre-hypertension) and in women [27]. In adults with essential hypertension an association with hyperuricaemia is very common.

Feig and Johnson found that about 90\% of adolescent hypertension is associated with hyperuricaemia [28]. The threshold for hypertension could be as low as $5.0-5.5 \mathrm{mg} /$ dL (0.30-0.33 $\mathrm{mmol} / \mathrm{L})$, clearly below the supersaturation value of $6.8 \mathrm{mg} / \mathrm{dL}(0.4 \mathrm{mmol} / \mathrm{L})$. Thus, it should be independent of the formation of monosodium crystals. They also showed an effect of allopurinol, where two thirds of subjects tested normalized their blood pressure [29]. Recently, a second study published a comparison of allopurinol with probenecid, a randomized, double-blind, placebo-controlled study, in pre-hypertensive obese adolescents. The urate-lowering effect was in the same range of 6.3 to $4.1 \mathrm{mg} / \mathrm{dL}(0.38$ to $0.24 \mathrm{mmol} / \mathrm{L})$. Both treatments were effective, with reductions of 10 and $9 \mathrm{mmHg}$ in systolic and diastolic blood pressures, respectively, suggesting that decreased urate was responsible for the effects and not decreased XO activity [30]. A systematic meta-analysis of 10 longitudinal studies (738 patients) that assessed the effect of allopurinol on blood pressure showed significant 3.3 and $1.3 \mathrm{mmHg}$ decreases in systolic and diastolic blood pressures, respectively [31]. However, a recent
Cochrane review only found one study fulfilling their strict criteria [29] and concluded that the data are insufficient to recommend this treatment [32]. Finally, it should be mentioned that losartan and some calcium channel blockers are uricosuric and reduce the risk of gout. Data also suggest that these agents may have a greater blood pressurelowering effect, because their uricosuric property [33].

\section{Chronic kidney disease (CKD)}

Animal studies with experimental hyperuricaemia (e.g., through inhibition of uricase) suggest a causative role for urate in renal disease models [34], especially if there is pre-existing renal impairment as in the $5 / 6$ nephrectomy model [35]. In humans the situation is more complicated. A number of cross-sectional studies have found an association of urate levels with decreased eGFR or microalbuminuria, but the interpretation is difficult, because CKD can elevate urate levels and hyperuricaemia might cause or aggravate CKD. When it comes to incident CKD, most studies show an independent association with serum urate levels. However, the analysis of the progression of CKD 3-4 and its relationship to urate levels show conflicting results, most studies finding no independent association with hyperuricaemia. This could indicate that urate is more a risk factor for the onset of CKD than its progression. When it comes to kidney transplant graft loss or reduction in graft function, data are also conflicting with most studies showing no independent association with serum urate levels [34]. However, a recent review is supportive of urate as risk factor for CKD [36].

There are at least four randomized interventional studies using allopurinol in renal disease. Siu et al. randomized 54 patients with CKD 3-4 to allopurinol or placebo for 12 months. Allopurinol decreased systolic blood pressure (from 140 to $127 \mathrm{mmHg}$; control unchanged at $135 \mathrm{mmHg}$ ) and slowed CKD progression (defined as $>40 \%$ rise in serum creatinine; 12 versus $42 \%$ of patients) [37]. Goicoechea et al. randomized 113 patients with eGFR $<60$ $\mathrm{mL} / \mathrm{min} / 1.73 \mathrm{~m}^{2}$ to allopurinol or usual treatment for 24 months. There was an effect on eGFR decline (defined as a decrease of $>0.2 \mathrm{~mL} / \mathrm{min} / 1.73 \mathrm{~m}^{2}$; adjusted HR 0.53 ) and hs-CRP (from 4.4 to 3.0 versus $3.4-3.2 \mathrm{mg} / \mathrm{l}$ ) favouring allopurinol treatment, and a beneficial effect on cardiovascular endpoints (7/57 versus 15/56), but no effect on blood pressure [38]. Momeni et al. randomized 40 patients with type 2 diabetes mellitus and diabetic nephropathy to allopurinol or placebo, with a reduction in proteinuria (from 1.8 to 1.0 versus 1.7 to $1.6 \mathrm{~g}$ per $24 \mathrm{~h}$ ) in the allopurinol-treated group [39]. Shi et al. randomized 40 IgA nephropathy patients to allopurinol or usual treatment for 6 months. There was indirect evidence for a reduction in blood pressure on allopurinol (the antihypertensive drug doses were reduced in $7 / 9$ cases with hypertension on allopurinol versus $0 / 9$ in the 
control group), but no difference in eGFR [40]. In a posthoc analysis of the RENAAL trial, losartan reduced urate levels by $0.16 \mathrm{mg} / \mathrm{dL}(0.01 \mathrm{mmol} / \mathrm{L})$ from $6.7 \mathrm{mg} / \mathrm{dL}(0.4$ $\mathrm{mmol} / \mathrm{L}$ ) during the first 6 months; adjustment for the urate effect indicated that $1 / 5$ of losartan's renoprotective effect could be attributed to this reduction in urate [41]. However, it is difficult to draw any firm or generalizable conclusion for CKD, although there could be an effect of allopurinol on blood pressure and possibly an effect on eGFR.

\section{Congestive heart failure (CHF)}

Gout is associated with CHF, subclinical measures of systolic dysfunction and mortality according to an analysis of the Framingham Offspring Study [42]. However, there also seems to be increased XO activity in the failing myocardium, perhaps due to hypoxia and apoptosis, resulting in accumulation of uric acid precursors (hypoxanthine and xanathine) and $\mathrm{XO}$-induced production of ROS, causing a vicious cycle of damage [43]. There are several studies showing an association between increased serum urate levels in CHF and morbidity and mortality [43-45]. Gotsman et al. [45] in an Israeli heart failure register-based study found that treatment with allopurinol in CHF was associated with improved survival.

A group evaluating data from the Beta-Blocker Evaluation of Survival Trial took a different approach [46]. They assumed that hyperuricaemia without CKD is primarily due to increased production of uric acid from the failing heart, while hyperuricaemia in patients with CKD is in large part due to impaired renal excretion of urate. The conclusion was that hyperuricaemia is associated with a poor outcome in CHF without CKD, but not in those with CHF and CKD. This suggests that hyperuricaemia in CHF without CKD might be ascribed to increased XO activity. Although the role of XO in CHF is not clearly established, it appears that its inhibition (independent of urate-lowering) in patients with hyperuricaemia may have a beneficial effect on endothelial cell function, myocardial function and ejection fraction, while in contrast, reducing urate levels with probenecid or benzbromarone does not improve endothelial cell function or haemodynamic impairment, despite a significant decrease in serum urate level [for references see 47-50]. These data suggest that increased $\mathrm{XO}$ activity, rather than the serum urate level per se, is involved in CHF pathophysiology.

\section{The metabolic syndrome, T2DM and obesity}

The patient with metabolic syndrome should have at least three of the following five clinical features: abdominal obesity, impaired fasting glucose, hypertriglyceridaemia, low HDL-cholesterol, and elevated blood pressure. An elevated serum urate concentration is commonly associated with the metabolic syndrome [51]; while the increase in serum urate has often been considered to be secondary, recent studies suggest that it may have an important contributory role [2]. First, elevated serum urate levels commonly precede insulin resistance, T2DM [52,53], and obesity [54], which is consistent with hyperuricaemia as a tentative causal factor; second, studies in cell culture and animal models have suggested a causative role for urate in models of the metabolic syndrome. Two mechanisms are suggested [2,23,55]: 1) hyperuricaemia-induced endothelial dysfunction, leading to reduced insulin-stimulated nitric oxide-induced vasodilatation in skeletal muscle, and as a consequence reduced glucose uptake in skeletal muscle; 2) inflammatory and oxidative changes induced by intracellular urate levels in adipocytes. For example, mice lacking $\mathrm{XO}$ (producing uric acid from xanthine) only have half the adipocyte mass of their wild-type littermates. A recent review [56] suggests a bidirectional and causal relationship between hyperuricaemia and hyperinsulinaemia, the former reducing nitric oxide bioavailability and the latter decreasing the renal excretion of urate. The renal clearance of urate has been found to be inversely related to insulin resistance [57], which is supported by experimental studies in healthy volunteers and hypertensive patients [58,59].

Polymorphisms in the uric acid transporter SLC2A9 (GLUT9) are associated with elevated serum urate and the risk of gout, but SLC2A9 polymorphisms are not associated with obesity or the metabolic syndrome phenotype. However, SLC2A9 exports urate out of cells [60,61], in contrast to the transporter URAT1 (SLC22A12), which mediates entry (uptake) of urate into cells. URAT1 is located on adipocytes $[62,63]$ and URAT1 transporter gene polymorphisms in hypertensive subjects are associated with body mass index (BMI), waist circumference, HDL cholesterol, and the metabolic syndrome; - they accounted for $7 \%$ of the variation of BMI in Caucasians. However, there was no such association in African Americans [64]. In support of an involvement of adipocytes is a study in obese mice with the metabolic syndrome [65]. These mice are hyperuricaemic and lowering urate levels with allopurinol improves their pro-inflammatory phenotype in adipose tissue, with decreased macrophage infiltration and reduced insulin resistance.

A recent clinical trial studied urate-lowering with benzbromarone in patients with CHF [50]. While there was no effect on the altered haemodynamics in these CHF patients, lowering urate did improve insulin resistance. However, it cannot be excluded that it may have been a secondary pharmacological effect of benzbromarone related to its PPAR agonist activity. In a small Polish study, 28 patients with CKD were switched from a regular fructose diet to a low fructose diet for 6 weeks, and then back again. There were significant reductions in fasting serum insulin and inflammatory biomarkers, and a trend toward reductions in serum urate and blood pressure [66]. 
Hyperuricaemia could be a risk factor for T2DM, but a causal link remains controversial. Thus, there are studies concluding an association, no association, and even an inverse association, and have been reviewed recently by Li et al. [56]. Obesity is associated with reduced lifeexpectancy, largely because of the increased risk of cardiovascular disease. However, approximately a third of obese individuals do not develop cardiovascular disease. This group is generally referred to as the 'metabolically healthy obese'. In a recent study, serum urate was the best predictor of 'metabolically unhealthy obesity' (defined as having features of the metabolic syndrome), with increased cardiovascular risk in adolescents and adults [67]. Some studies also suggest an independent association between non-alcoholic fatty liver disease (NAFLD) and hyperuricaemia [68]. Hyperuricaemia is also independently associated with the severity of steatosis and a poor response to therapy in patients with chronic hepatitis $\mathrm{C}$ infection [69].

It should also be mentioned that there is an increased incidence and prevalence of nephrolithiasis in patients with T2DM, and it is possible that treatment with a URAT1 inhibitor might, as a side effect, increase the risk of forming urate stones. With insulin resistance, although urinary urate levels are usually not increased (because of increased renal tubular reabsorption of urate), urinary ammonium excretion is reduced and urine $\mathrm{pH}$ is more acid, which increases the risk of urate crystallization [70].

\section{Atherosclerosis and cardiovascular events}

The Framingham Heart Study reported that urate was not a risk factor for cardiovascular events, because urate was not independent of hypertension [71]. A systematic review and meta-analysis determined the risk of coronary heart disease (CHD) associated with hyperuricaemia in 26 studies with 402,997 adults. It was found that hyperuricaemia may modestly increase the risk of CHD events independently of traditional CHD risk factors. Women were found to have a more pronounced increase in risk for CHD mortality than for men [72]. A similar meta-analysis was performed for hyperuricaemia and stroke (16 studies, 238,449 adults), showing that hyperuricaemia modestly increased the risk of stroke incidence and mortality, independent of known risk factors, but without gender difference [73].

The potential relationship between hyperuricaemia and cardiovascular events could be through hypertension, but it may also involve a direct relationship due to disturbed endothelial function as a consequence of reduced nitric oxide production. Endothelial dysfunction is believed to play a key role in the early development of atherosclerosis and precedes plaque formation [74]. Endothelialdependent flow-mediated vasodilatation of the brachial artery can assess, among other things, nitric oxide-induced vasodilatation. A recent review and meta-analysis [75] of $\mathrm{XO}$ inhibitors evaluated three outcome parameters and showed favourable changes in each one following $\mathrm{XO}$ inhibition: brachial artery flow-mediated dilatation (5 studies: $\mathrm{XO}$ inhibition $\mathrm{n}=75$, control $\mathrm{n}=69$ ) increased by $2.5 \%$ (95\% CI, 0.15-4.84); forearm blood flow responses to acetylcholine infusion (5 studies: $\mathrm{XO}$ inhibition $\mathrm{n}=74$, control $\mathrm{n}=74$ ) increased by $68.8 \%$ (95\% CI, 18.7-118.9; a percent change relative to the non-infused control arm); circulating markers of oxidative stress (malondialdehyde, 6 studies: $\mathrm{XO}$ inhibition $\mathrm{n}=78$, control $\mathrm{n}=68$ ) decreased by $0.56 \mathrm{nmol} / \mathrm{mL}$ (95\% CI, $0.26-0.87$ ). Three additional studies have been published following this review, two are positive [76,77] and one is negative [78]. However, it is noteworthy that short-term lowering of serum urate by intravenous uricase had no effect on forearm blood flow responses to acetylcholine and L-NMMA ( $\mathrm{n}=10$ patients and $\mathrm{n}=10$ healthy subjects [79]).

\section{Conclusion}

The present review of the available literature shows that there is an association between serum urate levels and hypertension, CKD, heart failure, the metabolic syndrome, obesity and cardiovascular events. However, as is often the case in the published literature, support is not unanimous. Understanding in the field is hampered by the difference in urate metabolism between laboratory animals and man, which makes animal studies difficult to interpret. Thus, there is limited evidence for a causal relationship. The interventional studies in man can be considered more as hypothesis-generating, since design quality, duration, and sample size are often insufficient to clarify the role of urate in cardiovascular disease. In addition, most interventional studies are with allopurinol, which is lowering urate via inhibition of $\mathrm{XO}$, leading to decreased production of ROS, which may have contributed to any apparent beneficial effect. A definitive answer to the question of whether urate-lowering therapy can reduce cardiovascular morbidity and mortality will, in the end, require large interventional trials, but it is doubtful that the safety profile of allopurinol is sufficient for such large-scale studies. The recently approved and emerging novel urate-lowering agents may have a better safety profile for these much needed larger and longer-term studies. Ideally, these studies would compare cardiovascular endpoints in patients treated with placebo versus $\mathrm{XO}$ and/or URAT1 inhibition, to establish both the benefits and mechanisms of treating hyperuricaemia.

A very recent online publication has used mendelian randomization to investigate the association of plasma uric acid (SLC2A9) with ischaemic heart disease and hypertension (Palmer et al, BMJ 2013;347:44262 doi: 10.1136/bmj. f4262) and concluded that there is no strong evidence for 
a causal association, and that the apparent link is confounded by body weight.

\section{Abbreviations}

BMI: Body mass index; CHD: Coronary heart disease; CHF: Congestive heart failure; CKD: Chronic kidney disease; GWAS: Genome-wide association studies; MS: Multiple sclerosis; NAFLD: Non-alcoholic fatty liver, disease; ROS: Reactive oxygen species; T2DM: Type 2 diabetes mellitus; XO: Xanthine oxidase.

\section{Competing interests}

DG is an employee of AstraZeneca and RU is consulting with AstraZeneca.

\section{Authors' contributions}

DG drafted the manuscript and both DG and RU revised it and approved the final manuscript. Both authors have read and approved the final manuscript.

\section{Acknowledgements}

The authors would like to thank Peter Morsing for initiating this work and James Mackay and his team for valuable input on the manuscript.

\section{Author details}

'Bioscience, CVMD iMED, AstraZeneca R\&D Mölndal, Mölndal, Sweden. ${ }^{2} U$ niversity College London, UCL Centre for Nephrology, Royal Free Campus, London, UK.

Received: 14 May 2013 Accepted: 19 July 2013

Published: 29 July 2013

\section{References}

1. Choi HK, Mount DB, Reginato AM: Pathogenesis of Gout. Ann Intern Med 2005, 143(7):499-516.

2. Feig DI, Kang DH, Johnson RJ: Uric acid and cardiovascular risk. N Engl J Med 2008, 359(17):1811-1821.

3. Choi HK, Curhan G: Soft drinks, fructose consumption, and the risk of gout in men: prospective cohort study. Br Med J 2008, 336:309-312.

4. Crittenden DB, Pillinger MH: New therapies for gout. Annu Rev Med 2013, 64:325-337.

5. Bobulescu IA, Moe OW: Renal transport of uric acid: evolving concepts and uncertainties. Adv Chronic Kidney Dis 2012, 19(6):358-371.

6. Hosomi A, Nakanishi T, Fujita T, Tamai I: Extra-renal elimination of uric acid via intestinal efflux transporter BCRP/ABCG2. PLoS One 2012, 7(2):e30456.

7. Dinour D, Bahn A, Ganon L, Ron R, Geifman Holtzman O, Knecht A, Gafter U, Ruth Rachamimov R, Sela BA, Gerhard Burckhardt G, Holtzman EJ: URAT1 mutations cause renal hypouricaemia type 1 in Iraqi Jews. Nephrol Dial Transplant 2011, 26(7):2175-2181.

8. Kolz M, Johnson T, Sanna S, Teumer A, Vitart V, Perola M, Mangino M, Albrecht E, Wallace C, Farrall M, Johansson A, Nyholt DR, Aulchenko Y, Beckmann JS, Bergmann S, Bochud M, Brown M, Campbell H, for the EUROSPAN Consortium, Connell J, Dominiczak A, Homuth G, Lamina C, McCarthy MI, for the ENGAGE Consortium, Meitinger T, Mooser V, Munroe P, Nauck M, Peden J, Prokisch H, Salo P, et al: Meta-analysis of 28,141 individuals identifies common variants within five new loci that influence uric acid concentrations. PLoS Genet 2009, 5(6):e1000504.

9. Yang Q, Köttgen A, Dehghan A, Smith AV, Glazer NL, Chen MH, Chasman DI, Aspelund T, Eiriksdottir G, Harris TB, Launer L, Nalls M, Hernandez D, Arking DE, Boerwinkle E, Grove ML, Li M, Kao WHL, Chonchol M, Haritunians T, Li G, Lumley T, Psaty BM, Shlipak M, Hwang SJ, Larsson MG, O'Donnell CJ, Upadhyay A, van Duijn CM, Hofman A, et al: Multiple genetic loci influence serum urate levels and their relationship with gout and cardiovascular disease risk factors. Circ Cardiovasc Genet 2010, 3(6):523-530.

10. Dinour D, Gray NK, Campbell S, Shu X, Sawyer L, Richardson W, Rechavi G, Amariglio N, Ganon L, Sela BA, Bahat H, Goldman M, Weissgarten J, Millar MR, Wright AF, Holtzman EJ: Homozygous SLC2A9 mutations cause severe renal hypouricemia. J Am Soc Nephrol 2010, 21(1):64-72.

11. Köttgen A, Albrecht E, Teumer A, Vitart V, Krumsiek J, Hundertmark C, Pistis G, Ruggiero D, O'Seaghdha CM, Haller T, Yang Q, Tanaka T, Johnson AD, Kutalik Z, Smith AV, Shi J, Struchalin M, Middelberg RPS, Brown MJ, Gaffo AL, Pirastu N, Li G, Hayward C, Zemunik T, Huffman J, Yengo L, Zhao JH, Demirkan A, Feitosa MF, Liu X, et al: Genome-wide association analyses identify 18 new loci associated with serum urate concentrations. Nat Genet 2013, 45(2):145-154.
12. Moskowitz JL, Piret SE, Lhotta K, Kitzler TM, Tashman AP, Velez E, Thakker RV, Kotanko P: Association between genotype and phenotype in uromodulin-associated kidney disease. Clin J Am Soc Nephrol. in press.

13. Juraschek SP, Kovell LC, Miller ER III, Gelber AC: Association of kidney disease with prevalent gout in the United States in 1988-1994 and 2007-2010. Sem Arthritis Rheumatism 2013, 42(6):551-561.

14. Khanna D, Fitzgerald JD, Khanna PP, Bae S, Singh MK, Neogi T, Pillinger MH, Merill J, Lee S, Prakash S, Kaldas M, Gogia M, Perez-Ruiz F, Taylor W, Liote' F, Choi H, Singh JA, Dalbeth N, Kaplan S, Niyyar V, Jones D, Yarows SA, Roessler B, Kerr G, King C, Levy G, Furst DE, Edwards NL, Mandell B, Schumacher HR, et al: 2012 American College of Rheumatology guidelines for management of gout. Part 1: Systematic nonpharmacologic and pharmacologictherapeutic approaches to hyperuricemia. Arthritis Care Res 2012, 64(10):1431-1446.

15. Yamanaka $\mathrm{H}$ : Japanese guideline for the management of hyperuricemia and gout: Second edition. Nucleosides Nucleotides Nucleic Acids 2011, 30(12):1018-1029.

16. Schlesinger N: Difficult-to-treat gouty arthritis. A disease warranting better management. Drugs 2011, 71(11):1413-1439.

17. Becker MAH, Ralph Schumacher HR, Espinoza LR, Wells AF, MacDonald P, Lloyd E, Lademacher C: The urate-lowering efficacy and safety of febuxostat in the treatment of the hyperuricemia of gout: the CONFIRMS trial. Arthritis Res Ther 2010, 12:R63.

18. Ryu HJ, Song R, Kim HW, Kim JH, Lee EY, Lee YJ, Song YW, Lee EB: Clinical risk factors for adverse events in allopurinol users. I Clin Pharmacol 2013, 53(2):211-216

19. Fleischmann R, Shen Z, Yeh L-T, Kerr B, Polvent E, Suster M, Hingorani V, Miner JN, Manhard K, Quart B: Lesinurad (RDEA594), a novel uricosuric agent, in combination with febuxostat shows significant additive urate lowering effects in gout patients with $100 \%$ response achieved for all combination dose regimens [abstract]. Ann Rheum Dis 2011, 70(Suppl. 3):188.

20. Kotz J: The gout pipeline crystallizes. Nature Rev Drug Discov 2012, 11 (6):425-426.

21. Ohno I, Yamaguchi Y, Saikawa H, Uetake D, Hikita M, Okabe H, Ichida K, Hosoya T: Sevelamer decreases serum uric acid concentration through adsorption of uric acid in maintenance hemodialysis patients. Inter Med 2009, 48(6):415-420.

22. Dalbeth N, So A: Hyperuriemia and gout: state of the art and future perspectives. Ann Rheum Dis 2010, 69(10):1738-1743.

23. So A, Thorens B: Uric acid transport and disease. J Clin Invest 2010, 120(6):1791-1799.

24. Álvarez-Lario B, Macarrón-Vivente J: Is there anything good in uric acid? QJM 2011, 104(12):1015-1024.

25. Mazzali M, Hughes J, Kim YG, Jefferson JA, Kang DH, Gordon KL, Lan HY, Kivlighn S, Johnson RJ: Elevated uric acid increases blood pressure in the rat by a novel crystal-independent mechanism. Hypertension 2001 38(5):1101-1106.

26. Mazzali M, Kanellis J, Han L, Feng L, Xia YY, Chen Q, Kang DH, Gordon KL, Watanabe S, Nakagawa T, Lan HY, Johnson RJ: Hyperuricemia induces a primary renal arteriolopathy in rats by a blood pressure-independent mechanism. Am J Physiol Renal Physiol 2002, 282(6):F991-F997.

27. Grayson PC, Kim SY, LaValley M, Choi HK: Hyperuricemia and incident hypertension: A systemic review and meta-analysis. Arthritis Care Res 2011, 63(1):102-110.

28. Feig DI, Johnson RJ: Hyperuricemia in childhood primary hypertension. Hypertension 2003, 42(3):247-252.

29. Feig DI, Soletsky B, Johnson RJ: Effect of allopurinol on blood pressure of adolescents with newly diagnosed essential hypertension: a randomized trial. J Am Med Assoc 2008, 300(8):924-932.

30. Soletsky B, Feig DI: Uric acid reduction rectifies prehypertension in obese adolescents. Hypertens 2012, 60(5):1148-1156.

31. Agarwal V, Hans N, Messerli FH: Effect of allopurinol on blood pressure: A systematic review and meta-analysis. J Clin Hypertens 2013, 16(6):435-442.

32. Gois PHF, Souza ERDM: Pharmacotherapy for hyperuricemia in hypertensive patients. Cochrane Library 2013, 1. http://onlinelibrary.wiley.com/doi/10.1002/ 14651858.CD008652.pub2/full.

33. Choi HK, Soriano LC, Zhang Y, Rodrigues LAG: Antihypertensive drugs and risk of incident gout among patients with hypertension: population based case-control study. Br Med J 2012, 344:d8190. 
34. Nashar K, Fried LF: Hyperuricemia and the Progression of Chronic Kidney Disease: Is uric acid a marker or an independent risk factor. Adv Chronic Kidney Dis 2012, 19(6):386-391.

35. Kang DH, Nakagawa T, Feng L, Watanabe S, Han L, Mazzali M, Truong L, Harris $\mathrm{R}$, Johnson RJ: A role for uric acid in the progression of renal disease. J Am Soc Nephrol 2002, 13(12):2888-2897.

36. Johnson RJ, Nakagawa T, Jalal D, Sánchez Lozada LG, Kang DH, Ritz E: Uric acid and chronic kidney disease: which is chasing which? Nephrol Dial Transplant 2013. in press.

37. Siu YP, Leung KT, Tong MK, Kwan TH: Use of allopurinol in slowing the progression of renal disease through its ability to lower serum uric acid level. Am J Kidney Dis 2006, 47(1):51-59.

38. Goicoechea M, de Vinuesa SG, Verdalles U, Ruiz-Caro C, Ampuero J, Rincón A, Arroyo D, Luño J: Effect of allopurinol in chronic kidney disease progression and cardiovascular risk. Clin J Am Soc Nephrol 2010, 5(8):1388-1393.

39. Momeni A, Shahidi S, Seirafian S, Taheri S, Kheiri S: Effect of allopurinol in decreasing proteinuria in Type 2 diabetic patients. Iranian J Kid Dis 2010 4(2):128-132.

40. Shi $Y$, Chen $W$, Jalal $D$, et al: Clinical outcome of hyperuricemia in $\lg A$ nephropathy: a retrospective cohort study and randomized controlled trial. Kidney Blood Press Res 2012, 35(3):153-160.

41. Miao Y, Ottenbros SA, Laverman GD, Brenner BM, Cooper ME, Parving HH, Grobbee DE, Shahinfar S, de Zeeuw D, Lambers Heerspink HJ: Effect of a reduction in uric acid on renal outcomes during losartan treatment: $A$ post hoc analysis of the reduction of endpoints in non-insulin -dependent diabetes mellitus with the angiotensin ii antagonist losartan trial. Hypertension 2011, 58(1):2-7.

42. Krishnan E: Gout and the risk for incident heart failure and systolic dysfunction. Br Med J Open 2012, 2(1):e000282

43. Tamariz L, Verma S: Uric acid as a predictor of all-cause mortality in heart failure: A Meta-analysis. Congest Heart Fail 2011, 17(1):25-30.

44. Hamaguchi S, Furumoto T, Tsuchihashi-Makaya M, Goto K, Goto D, Yokota T, Kinugawa S, Yokoshiki H, Takeshita A, Tsutsui $\mathrm{H}$, for the JCARE-CARD Investigators: Hyperuricemia predicts adverse outcome in patients with heart failure. Internat J Cardiol 2011, 151(2):143-147.

45. Gotsman I, Kern A, Lotan C, Zwas DR: Changes in uric acid levels and allopurinol use in chronic heart failure: Association with improved survival. J Cardiac Failure 2012, 18(9):694-701.

46. Filippatos GS, Ahmed MI, Gladden JD, Aban IB, Love TE, Sanders PW, Pitt B, Anker SD, Ahmed A: Hyperuricemia, chronic kidney disease, and outcomes in heart failure: potential mechanistic insights from epidemiological data. Eur Hear J 2011, 32(6):712-720.

47. Harzand A, Tamariz L, Hare JM: Uric acid, heart failure survival, and the impact of xanthine oxidase inhibition. Congest Heart Fail 2012, 18(3):179-182

48. George J, Carr E, Davies J, Belch JJF, Struthers A: High-dose allopurinol improves endothelial function by profoundly reducing vascular oxidative stress and not by lowering UA. Circulation 2006, 114(23):2508-2516.

49. Noman A, Ang DSC, Ogston S, Lang CC, Struthers AD: Effect of high-dose allopurinol on exercise in patients with chronic stable angina: a randomised, placebo controlled crossover trial. Lancet 2010 375(9732):2161-2167.

50. Ogino K, Kato M, Furuse $Y$, Kinugasa $Y$, Ishida K, Osaki S, Kinugawa T, Igawa O, Hisatome I, Shigemasa C, Anker SD, Doehner W: Uric acidlowering treatment with benzbromarone in patients with heart failure: a double- blind placebo-controlled crossover preliminary study. Circ Heart Fail 2010, 3(1):73-81

51. Tsouli SG, Liberopoulos EN, Mikhailidis DP, Athyros VG, Elisaf MS: Elevated serum uric acid levels in metabolic syndrome: an active component or an innocent bystander? Metabolism 2006, 55(10):1293-1301.

52. Kodama S, Saito K, Yachi Y, Asumi M, Sugawara A, Totsuka K, Saito A, Sone $\mathrm{H}$ : Association between serum uric acid and development of type 2 diabetes. Diabetes Care 2009, 32(9):1737-1742.

53. Dehghan A, van Hoek M, Sijbrands EJ, Hofman A, Witteman JC: High serum uric acid as a novel risk factor for type 2 diabetes. Diabetes Care 2008, 31(2):361-362

54. Masuo K, Kawaguchi H, Mikami H, Ogihara T, Tuck ML: Serum uric acid and plasma norepinephrine concentrations predict subsequent weight gain and blood pressure elevation. Hypertension 2003, 42(3):474-480.
55. Kanellis J, Kang DH: Uric acid as a mediator of endothelial dysfunction, inflammation, and vascular disease. Semin Nephrol 2005, 25(1):39.42.

56. Li C, Hsieh MC, Chang SJ: Metabolic syndrome, diabetes, and hyperuricemia. Curr Opin Rheumatol 2013, 25(2):210-216

57. Facchini F, Chen YD, Hollenbeck CB, Reaven GM: Relationship between resistance to insulin-mediated glucose uptake, urinary uric acid clearance, and plasma uric acid concentration. J Am Med Assoc 1991 266(21):3008-3011.

58. Quinones Galvan A, Natali A, Baldi S, Frascerra S, Sanna G, Ciaciaro D, Ferrannini E: Effect of insulin on uric acid excretion in humans. Am J Physiol 1995, 268(1):E1-E5.

59. Muscelli E, Natali A, Bianchi S, Bigazzi S, Quinones Galvan AQ, Sironi AM, Frascerra $S$, Ciociaro D, Ferrannini E: Effect of insulin on renal sodium and uric acid handling in essential hypertension. Am J Hypertens 1996, 9(8):746-752.

60. Bibert S, Hess SK, Firsov D, Thorens B, Geering K, Horisberger JD, Bonny O: Mouse GLUT9: evidences for a urate uniporter. Am J Physiol Renal Physiol 2009, 297(3):F612-619.

61. Anzai N, Ichida K, Jutabha P, Kimura T, Babu E, Jin CJ, Srivastava S, Kitamura $\mathrm{K}$, Hisatome I, Endou H, Sakurai H: Plasma urate level is directly regulated by a voltage-driven urate efflux transporter URATV1 (SLC2A9) in humans. J Biol Chem 2008, 283(5):26834-26838.

62. Price KL, Sautin YY, Long DA, Zhang L, Miyazaki H, Mu W, Endou H, Johnson $\mathrm{RJ}$ : Human vascular smooth muscle cells express a urate transporter. J Am Soc Nephrol 2006, 17(7):1791-1795.

63. Sautin $Y Y$, Nakagawa T, Zharikov S, Johnson RJ: Adverse effects of the classic antioxidant uric acid in adipocytes: NADPH oxidase mediated oxidative/nitrosative stress. Am J Physiol Cell Physiol 2007, 293(2):C584-596.

64. Shafiu M, Johnson RJ, Turner ST, Langaee T, Gong Y, Chapman AB, Gums JG, Johnson JA: Urate transporter gene SLC22A12 polymorphisms associated with obesity and metabolic syndrome in Caucasians with hypertension. Kidney Blood Press Res 2012, 35(6):477-482

65. Baldwin W, McRae S, Marek G, Wymer D, Pannu V, Baylis C, Johnson RJ, Sautin $Y Y$ : Hyperuricemia as a mediator of the proinflammatory endocrine imbalance in the adipose tissue in a murine model of the metabolic syndrome. Diabetes 2011, 60(4):1258-1269.

66. Brymora A, Flisinski M, Johnson RJ, Goszka G, Stefanska Manitius J: Lowfructose diet lowers blood pressure and inflammation in patients with chronic kidney disease. Nephrol Dial Transplant 2012, 27(2):608-612.

67. Mangge H, Zelzer S, Puerstner P, Schnedl WJ, Reeves G, Postolache TT, Weghuber D: Uric acid best predicts metabolically unhealthy obesity with increased cardiovascular risk in youth and adults. Obesity 2013, 21(1):E71-E77.

68. Petta S, Camma CD, Cabibi D, Di Marco V, Craxi A: Hyperuricemia is associated with histological liver damage in patients with non-alcoholic fatty liver disease. Aliment Pharmacol Therapeut 2011, 24(7):757-766.

69. Petta S, Macaluso SF, Cammà C, Di Marco V, Cabibi D, Craxì A: Hyperuricaemia: another metabolic feature affecting the severity of chronic hepatitis because of HCV infection. Liver Int 2012, 32(9):1443-1450.

70. Bell DSH: Beware of the low urine $\mathrm{pH}$-the major cause of the increased prevalence of nephrolithiasis in the patient with type 2 diabetes. Diabetes Obes Metab 2012, 14(4):299-303.

71. Culleton BF, Larson MG, Kannel WB: Serum uric acid and risk for cardiovascular disease and death: the Framingham Heart Study. Ann Intern Med 1999, 131(1):7-13.

72. Kim SY, Guevara JP, Kim KM, Choi HK, Heitjan DF, Albert DA: Hyperuricemia and coronary heart disease: A systematic review and meta-analysis. Arthritis Rheum 2010, 62(2):170-180

73. Kim SY, Guevara JP, Kim KM, Choi HK, Heitjan DF, Albert DA: Hyperuricemia and risk of stroke: A systematic review and meta-analysis. Arthritis Rheum 2009, 61(7):885-892.

74. Rablink TJ, Luscher TF: Endothelial nitric oxide synthase: host defense enzyme of the endothelium? Arterioscler Thromb Vasc Biol 2006, 26(2):267-271

75. Higgins P, Dawson J, Lees KR, McArthur K, Quinn TJ, Walters MR: Xanthine oxidase inhibition for the treatment of cardiovascular disease: a systematic review and meta-analysis. Cardiovasc Therap 2012, 30(4):217-226 
76. Rajendra NS, Ireland S, George J, Belch JJF, Lang CC, Struthers AD: Mechanistic insights into the therapeutic use of high-dose allopurinol in angina pectoris. J Am Coll Cardiol 2011, 58(8):820-828.

77. Dogan A, Yarlioglues M, Kaya MG, Karadag Z, Dogan S, Ardic I, Dogdu O, Kilinc Y, Zencir C, Akpek M, Ozdogru I, Oguzhan Kalay AN: Effect of long-term and high-dose allopurinol therapy on endothelial function in normotensive diabetic patients. Blood Press 2011, 20(3):182-187.

78. Greig D, Alcaino H, Castro PF, Garcia L, Verdejo HE, Navarro M, López R, Mellado R, Tapia F, Gabrielli LA, Nogerol C, Chiong M, Godoy I, Lavandero S: Xanthine-oxidase inhibitors and statins in chronic heart failure: Effects on vascular and functional parameters. J Heart Lung Transp/ 2011, 30(4):408-413.

79. Waring WS, McKnight JA, Webb DJ: Lowering serum urate does not improve endothelial function in patients with type 2 diabetes. Diabetologia 2007, 50(12):2572-2579.

doi:10.1186/1471-2369-14-164

Cite this article as: Gustafsson and Unwin: The pathophysiology of hyperuricaemia and its possible relationship to cardiovascular disease, morbidity and mortality. BMC Nephrology 2013 14:164.

\section{Submit your next manuscript to BioMed Central and take full advantage of:}

- Convenient online submission

- Thorough peer review

- No space constraints or color figure charges

- Immediate publication on acceptance

- Inclusion in PubMed, CAS, Scopus and Google Scholar

- Research which is freely available for redistribution 